\title{
Prevalence of cigarette smoking among college students in Iran: An updated systematic review and meta-analysis of observational studies
}

\author{
Mahmoud Khodadost ${ }^{1,2}$, Khadije Maajani ${ }^{3}$, Alireza Noroozi ${ }^{4,5}$, Seyed Abbas Motevalian ${ }^{6,2}$, Morteza Naserbakht ${ }^{7}$, \\ Fatemeh Sarvi ${ }^{8}$, Roohollah Seddigh ${ }^{6}$, Leila Jamshidi ${ }^{9}$, Samira Yavari ${ }^{9}$, Malihe Khoramdad ${ }^{2}$, Ebrahim Ghodusi ${ }^{9}$, \\ Ahmad Hajebi*6 (1)
}

Abstract

Background: Cigarette smoking is known as a gateway drug for illicit drug use in youth. The objective of this study is to assess the prevalence of cigarette smoking in the college students in Iran.

Methods: We searched electronic databases including Scopus, Medline/PubMed, Google Scholar and Web of Science, and national databases such as Magiran, Scientific Information Database, Iranmedex, Medlib, Irandoc, and IranPsych from 1946 to 21 st July 2018 without any language restriction using a proper search strategy. We used a random effect model to calculate the pooled prevalence of cigarette smoking in college students in Iran. Chi-square test and $\mathrm{I}^{2}$ index were used to evaluate the heterogeneity between the studies. We used the meta-regression and subgroup analysis to assess the potential source of heterogeneity. Stata software, version 11 (StataCorp, TX) was used for all statistical analysis.

Results: We included 60 eligible articles in our study. The pooled prevalence of cigarette smoking at least once in the lifetime was 19\% (95\%CI: 17-22). The $\mathrm{I}^{2}$ index indicated considerable between-study heterogeneity $\left(\mathrm{I}^{2}=98 \%, \mathrm{p}<0.001\right)$. The pooled prevalence of cigarette smoking at least once in the lifetime in males and females was $28 \%$ (95\% CI: 23-34) and 9\% (95\% CI: 6-13), respectively. In multivariable meta-regression, a significant association was shown between the year of study $(\beta=-13.1, p=0.011)$ and sampling method $(\beta=-12.8 \mathrm{p}=0.017)$ and daily use in the last month.

Conclusions: Increasing prevalence of smoking among Iranian university students is an important health priority. Increasing preventive and health education programs are recommended.

Keywords: University students, Smoking, Tobacco, Meta-analysis

Conflicts of Interest: None declared

Funding: The Substance Abuse Prevention and Treatment Office (SAPTO), Ministry of Health and Medical Education (MOHME) of Iran

*This work has been published under CC BY-NC-SA 1.0 license.

Copyright $\subseteq$ Iran University of Medical Sciences

Cite this article as: Khodadost M, Maajani Kh, Noroozi A, Motevalian SA, Naserbakht M, Sarvi F, Seddigh R, Jamshidi L, Yavari S, Khoramdad M, Ghodusi E, Hajebi A. Prevalence of cigarette smoking among college students in Iran: An updated systematic review and meta-analysis of observational studies. Med J Islam Repub Iran. 2020 (8 Dec);34:165. https://doi.org/10.47176/mjiri.34.165

Corresponding author: Dr Ahmad Hajebi, hajebi.a@iums.ac.ir

1. Department of Epidemiology, School of Public Health, Shahid Beheshti University of Medical Sciences, Tehran, Iran

2. Department of Epidemiology, School of Public Health, Iran University of Medical Sciences, Tehran, Iran

3. Department of Epidemiology and Biostatistics, School of Public Health, Tehran University of Medical Sciences, Tehran, Iran

4. Iranian National Center for Addiction Studies (INCAS), Tehran University of Medical Sciences, Tehran, Iran

5. Neuroscience and Addiction Studies Department, School of Advanced Technologies in Medicine (SATIM), Tehran University of Medical Sciences, Tehran, Iran

6. Research Center for Addiction and Risky Behaviors (ReCARB), Psychosocial Health Research Institute (PHRI), Iran University of Medical Sciences, Tehran, Iran

7. Mental Health Research Center, Psychosocial Health Research Institute, Iran University of medical sciences, Tehran, Iran

8. Department of Epidemiology, School of Public Health, Larestan University of Medical Sciences, Larestan, Iran

9. Substance Abuse Prevention and Treatment Office (SAPTO), Ministry of Health and Medical Education (MoHME), Tehran, Iran

\section{$\uparrow$ What is "already known" in this topic:}

Cigarette smoking was known as gateway drug in vulnerable populations, especially in college students. There is no consensus about the recent trends and prevalence rate of cigarette smoking in Iranian university students. Therefore, the estimate of the pooled prevalence of Cigarette smoking is important.

$\rightarrow$ What this article adds:

The pooled prevalence of cigarette smoking in college students was $19 \%$. Increasing prevalence of smoking among Iranian university students is an important health priority. These results could be good bases to help evidence-based policymaking for the health sector policymakers. 


\section{Introduction}

Cigarette smoking is known as a serious public health problem and an important cause of preventable morbidity and mortality in the world (1). According to the global burden of disease study in 2010, cigarette smoking is the second leading cause of death globally (2) and has adverse health effects such as coronary heart disease (CHD), stroke, serious cancers including lung, larynx, esophagus, pancreas, liver, cervix, bladder, mouth, etc. (3). It is estimated 1.3 billion people smoke worldwide and WHO estimated that over 6 million people die annually due to cigarette smoking (WHO 2002). According to the WHO estimates in 2010, the prevalence of smoking in the Iranian population was about $12 \%$. Recent national surveys from 2005 to 2011 in adults between 15-64 years in Iran indicated that cigarette smoking use is decreasing (4). The national survey reported that the current use of cigarette smoking in men was from $24.1 \%$ in 2005 to $20.8 \%$ in 2011 and in women were from $4.3 \%$ in 2005 to $0.9 \%$ in 2011. Also, daily use of cigarette smoking in men was from $20.9 \%$ in 2005 to $19.2 \%$ in 2011 and for women was from $2.9 \%$ in 2005 to $0.6 \%$ in 2011 . The prevalence of smoking in college students of some neighborhood countries was reported $11 \%$ to $30 \%(5-7)$. The Prevalence rate of Cigarette smoking in the general population in Iran was reported $11.9 \%$ in 2007 . Also the prevalence of cigarette smoking among Iranian youth was increasing 1). Various studies conducted in Iran reported the prevalence of cigarette smoking in college students from $9.8 \%$ to $18.48 \%$ (8$10)$. Thus, because there is no consensus about the recent prevalence rate of cigarette smoking in Iranian university students and because of notable increased in the prevalence rate of cigarette smoking among university student in Iran, we aimed to calculate the prevalence rate of cigarette smoking in college students by meta-analysis.

\section{Methods}

We used a universal systematic review through various national and international electronic databases to identify studies that report the prevalence of smoking among university students in Iran. In this article, we used a preferred item for reporting systematic review and meta-analysis (PRISMA) guidelines to present the results.

\section{Search strategy}

We conducted an initial search from 1946 to July 21, 2018, in various international (CINAHL, Medline/PubMed, EMBASE, PsycINFO and Web of Science), regional (IMEMR), and national (Magiran, Scientific Information Database, Iranmedex, Medlib, Irandoc, and IranPsych) databases. The PICO of systematic review and meta-analysis was used to retrieve and screen the related studies. We used various combinations of related keywords to specify the geographic location (i.e., country and province names), target population (e.g., university students) and type of substance (e.g., tobacco, smoking, cigarette smoking). We did not limit searches by language.

For national databases, both English and Farsi key terms were used. We used the EndNote $\mathrm{X}^{7}$ software to screen the citations based on inclusion and exclusion criteria from various online databases and additional documents retrieved through other sources. We also searched the key journals in the field of substance use and mental health and assessed the reference section of retrieved studies or national reports documents to identify the related citations.

\section{Eligibility criteria}

The following eligibility criteria were used to screen the retrieved studies.

1. All observational studies that reporting data on the prevalence of cigarette smoking, including cohort studies, cross-sectional studies, case-control studies and the related regional and national surveys were included.

2. We included studies that report data on smoking use through self-rated questionnaires or interviews among university students.

3 . We limited our geographic scope to studies conducted within Iran.

4. For the study population, we included studies conducted among university students at the time of the study.

5. All scientific document types such as original articles, national reports, and surveys were included.

Exclusion criteria

1. We excluded documents not reporting epidemiologic data and also not reporting original data.

2. We excluded the review articles, systematic reviews, meta-analyses, case reports, case-series studies and qualitative studies.

3 . Studies with a sample size less than 100 were considered to be underpowered and also prone to a wider range of biases and thus were also excluded.

4. Studies conducted among Iranian college students residing outside of Iran.

5. We excluded studies in the general population, high school students, and other age and gender-specific groups that did not include university students. We did not set any limits on study implementation or publication year.

\section{Study selection and quality assessment}

We screened studies in a stepwise fashion. Two authors (KM \& MK) reviewed the studies by title, abstract and full text independently, based on eligibility criteria. Documents with disagreement were reconsidered by the two reviewers, and a third coauthor (AN) was evaluated the papers if needed. We used strengthening the reporting of observational studies in epidemiology (STROBE) checklist to investigate the risk of bias and the quality of each eligible study. The studies were categorized into three groups; studies receiving more than 80 percent of the total score were considered as high quality, $60-79 \%$ of the total scores as intermediate quality and $30-59 \%$ of the total score were classified as low quality. Two authors $(\mathrm{KH}, \mathrm{M}$ and M.KH) were conducting the quality assessment of included papers. The agreement among two reviewers was calculated using weighted Kappa (86\%). 


\section{Data extraction}

MK \& KM extracted data from the retrieved studies and discussed disagreements with the third coauthor (AN) as indicated. We used the structured sheets in Microsoft Excel ${ }^{\circledR}$ to extract the data including (1) authors, (2) publication year, (3) publication type, (4) site/s of study, (5) study implementation year, (6) type of study, (7) sampling method, (8) study population and sample size, (9) data gathering method, (10) language (Farsi, English), (11) Study scale (city, province, sub-national, national), (12) number of recruitment sites, (13) gender distribution, (14) age characteristics, (15) key socioeconomic indicators, (16) type of university, (17) major of university student, (18) prevalence of smoking.

\section{Statistical analysis}

We used the Q test at 5\% significant level and $I^{2}$ index to investigate the statistical heterogeneity; according to the result of these tests we used a random effect model to calculated summary pooled prevalence of cigarette use and $95 \%$ confidence intervals, weighted by the inverse of the variance. We used the binomial distribution to calculate the standard error in each study. We illustrated data in the form of forest plots for the above sub-populations wherever such data was available. We used the Metaprop command in Stata to conduct the meta-analysis.

Meta-regression analysis was used based on sample size, year of the study and sampling methods to investigate the potential source of heterogeneity.

We did not assess the publication bias because the pooled prevalence is a positive number as a proportion effect size and if we saw asymmetry in the funnel plot, it is not due to the publication bias. To perform the statistical analysis, we used Stata-11 (StataCorp, College Station, TX, USA).

\section{Results}

\section{Descriptive Statistics}

In the electronic database searching, the total number of 1917 publications was enrolled, and 4 studies were identified by the other sources. In the final step, 60 documents were enrolled in the meta-analysis based on the screening process by applying inclusion and exclusion criteria (Fig. 1). Table 1 reports the studies characteristics enrolled in the systematic review and meta-analysis.

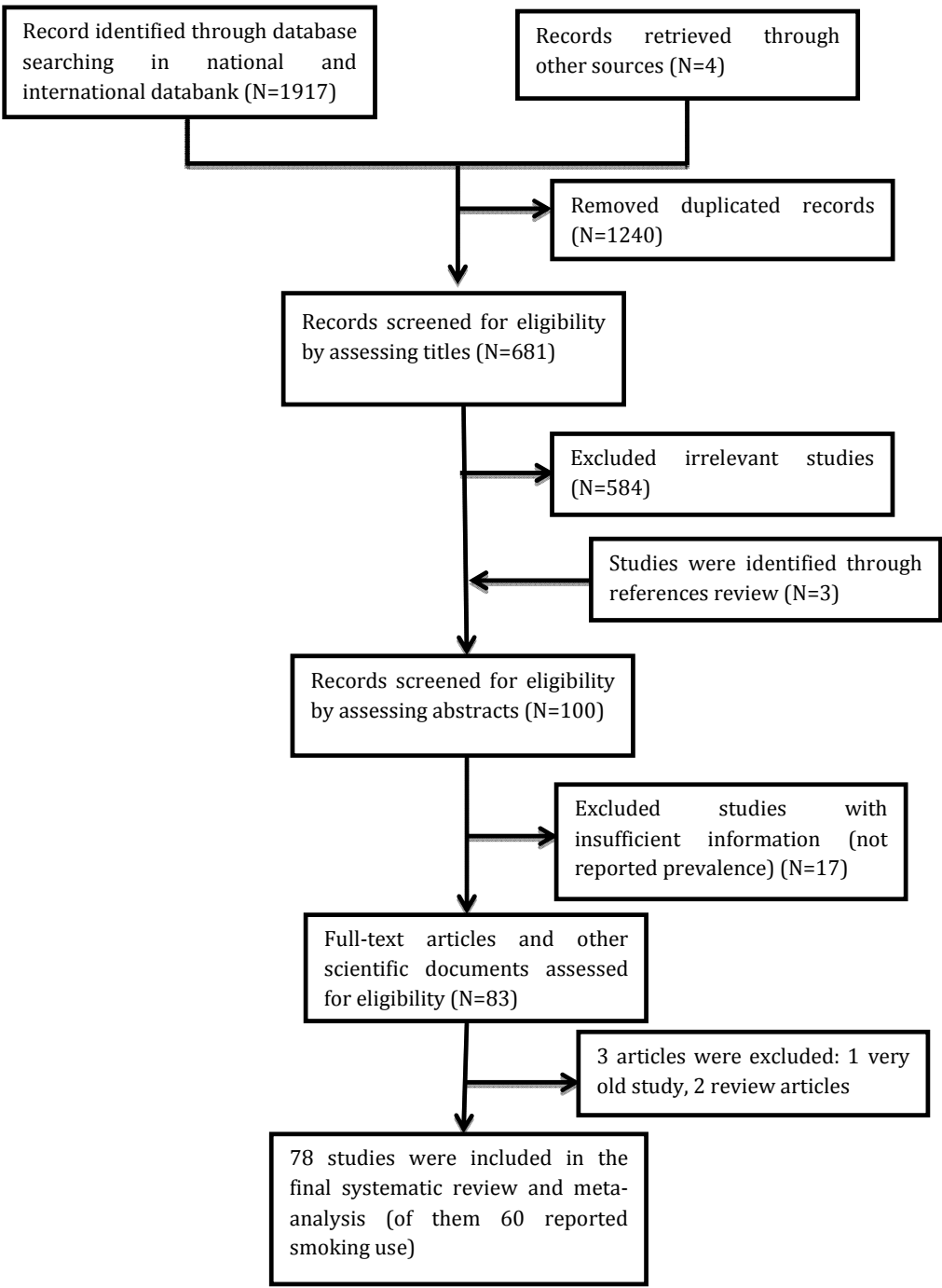

Fig. 1. The PRISMA flow diagram of different phases involved in searching and for relevant publications 
Table 1. The characteristic of studies were enrolled in the systematic review and meta-analysis

\begin{tabular}{|c|c|c|c|c|c|c|c|c|c|c|c|c|}
\hline \multirow[t]{2}{*}{ Study ID } & \multirow[b]{2}{*}{ First author } & \multirow{2}{*}{$\begin{array}{l}\text { Year of } \\
\text { study }\end{array}$} & \multirow[t]{2}{*}{ Study location } & \multirow{2}{*}{$\begin{array}{c}\text { Age in years } \\
\text { (Mean) }\end{array}$} & \multirow[b]{2}{*}{ Sampling methods } & \multirow[b]{2}{*}{$\begin{array}{l}\text { Sample } \\
\text { size (n) }\end{array}$} & \multirow[b]{2}{*}{$\begin{array}{c}\begin{array}{c}\text { Response } \\
\text { rate }(\%)\end{array} \\
\end{array}$} & \multirow[b]{2}{*}{ Daily } & \multirow[b]{2}{*}{$\begin{array}{l}\text { Last } \\
\text { week }\end{array}$} & \multicolumn{3}{|c|}{ Prevalence (\%) } \\
\hline & & & & & & & & & & $\begin{array}{c}\text { Last } \\
\text { month }\end{array}$ & $\begin{array}{l}\text { Last } \\
\text { year }\end{array}$ & Lifetime \\
\hline $\mathrm{W} 1^{\mathrm{d}}$ & Afrashteh S \& et al & 2016 & Bushehr & 22.1 & Random sampling & 977 & 100 & - & 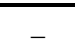 & & 10 & \\
\hline W2 & Ahmadabadi S \& et al & 2015 & Tehran & 21.7 & Multistage random sampling & 1173 & 100 & & - & $1 \overline{3} .9$ & - & $3 \overline{0.6}$ \\
\hline W3 & Ahmadi J \& et al & 2000 & Shiraz & 23.23 & Random Cluster Sampling & 501 & 90.22 & $3 \overline{6} .1$ & - & & - & 54.9 \\
\hline W4 & Ahmadi $J$ \& et al & 2000 & Shiraz & 20.69 & Census & 400 & 100 & 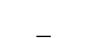 & - & $1 \overline{0.8}$ & - & 25.3 \\
\hline W5 & Ahmadi J \& et al & 2001 & Shiraz & 20.5 & Random sampling & 184 & 100 & - & - & & - & 34.8 \\
\hline W6 & Akbari Zard khaneh S \& et al & 2011 & Survey $^{\mathrm{c}}$ & 21.01 & Stratified random sampling & 8352 & 100 & - & - & - & - & 18.78 \\
\hline W7 & Allahverdipour $\mathrm{H} \&$ et al & 2011 & Tabriz & 22.09 & Random Cluster sampling & 2128 & 86.1 & - & - & - & - & 15.6 \\
\hline W8 & Amin-Esmaeili M \& et al & 2006 & Tehran & 20.4 & Census & 1761 & 96.8 & $\overline{3.4}$ & $\overline{4.8}$ & 8.2 & $1 \overline{2} .5$ & 16.9 \\
\hline W8 & Amin-Esmaeili M \& et al & 2007 & Tehran & 20.2 & Census & 1736 & 96.1 & 4 & 5.2 & 7.8 & 13.2 & 17.6 \\
\hline W8 & Amin-Esmaeili M \& et al & 2008 & Tehran & 20.2 & Census & 1750 & 90.7 & 2.9 & 3.8 & 6.1 & 10.8 & 14.3 \\
\hline W8 & Amin-Esmaeili M \& et al & 2009 & Tehran & 20.1 & Census & 15.61 & 90.6 & 1.8 & 3.2 & 5.8 & 10.1 & 13.3 \\
\hline W9 & Askarian M \& et al & 2011 & Shiraz & 21 & Simple random sampling & 600 & 100 & 10.1 & _ & _ & - & \\
\hline W10 & Babaei Heydarabadi A \& et al & 2013 & Tehran & & Random sampling & 604 & 100 & & - & & - & 30.7 \\
\hline W11 & Bahreinian A \& et al & 2001 & Tehran & $\overline{22}$ & Random Cluster Sampling & 566 & 100 & $3 . \overline{3} 5$ & - & - & - & 9.01 \\
\hline W12 & Dehghani KH \& et al & 2009 & Yazd & 22 & Random sampling & 534 & 100 & 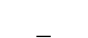 & - & - & - & 14.4 \\
\hline W13 & Eslami A \& et al & 2013 & Isfahan & 23.02 & Random sampling & 264 & 91.29 & - & - & & & 21.2 \\
\hline W14 & Fajani S \& et al & 2013 & Isfahan & & Stratified random sampling & 1801 & 83.95 & - & - & $3 \overline{2} .8$ & 33.79 & \\
\hline W15 & Ghanizadeh A \& et al & 1999 & Shiraz & 22.35 & Random sampling & 220 & 96.82 & - & - & & - & 52.38 \\
\hline W16 & Goreishi A \& et al & 2010 & Zanjan & 21.3 & Stratified random sampling & 1340 & 89.55 & - & - & $3 . \overline{0} 8$ & - & 16 \\
\hline W17 & Heydari T \& et al & 2013 & Jahrom & 21.15 & Random sampling & 1149 & 100 & - & - & 2.52 & - & 17 \\
\hline W18 & Jalilian F \& et al & 2012 & Kermanshah & 22.68 & Random sampling & 385 & 82.08 & - & - & & - & 14.5 \\
\hline W19 & Kabir K \& et al & 2014 & Karaj & 22.4 & Random Cluster sampling & 1959 & 94 & - & - & $\overline{4.5}$ & - & \\
\hline W20 & Kiamarsi A \& et al & 2010 & Ardabil & 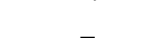 & Random sampling & 330 & 94.85 & - & - & 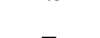 & - & $1 \overline{3} .1$ \\
\hline W21 & Majidpour A \& et al & 2004 & Ardabil & - & Census & 1106 & 100 & - & - & - & - & 13.9 \\
\hline W22 & Mardani H \& et al & 2010 & Bandar Abbas & 25.54 & Stratified random sampling & 350 & 88.57 & - & - & - & - & 15.48 \\
\hline W23 & Moayedi F \& et al & 2015 & Hormozgan & 22.7 & Random sampling & 350 & 97.7 & $\overline{20}$ & - & - & - & \\
\hline W24 & Mohtasham Amiri Z \& et al & 2005 & Astara & 24.2 & Stratified random sampling & 1380 & 88.84 & 17.69 & - & $1 \overline{9} .6$ & - & $2 \overline{1} .8$ \\
\hline W25 & Mohtasham Amiri Z \& et al & 2005 & Guilan & 22.2 & Multistage random sampling & 3958 & 93.48 & 16.02 & - & 19.5 & - & \\
\hline W26 & Monirpoor N \& et al & 2013 & Karaj,Takestan & 22.55 & Stratified random sampling & 1053 & 100 & . & - & - & - & $2 \overline{0} .4$ \\
\hline W27 & Mortazavi GH \& et al & 2003 & Birjand & 21.47 & Multistage random sampling & 1000 & 87.00 & - & - & - & - & 31.5 \\
\hline W28 & Mozafarinia R \& et al & 2014 & Tehran & 22.4 & Random sampling & 422 & 100 & 8.5 & 5.2 & 3.8 & 5.2 & 26.3 \\
\hline W29 & Nakhaee N \& et al & 2009 & Kerman & $21.2 \pm 2.1$ & Random sampling & 1677 & 96 & & & 11 & & 31 \\
\hline W30 & Refahi A \& et al & 2012 & Zahedan & & Random Cluster sampling & 1014 & 98.9 & & & 7.6 & 11.7 & $22 \%$ \\
\hline
\end{tabular}

a. Survey includes 5 universities from Iran: Tehran University, Isfahan University of Technology, Shahid Bahonar University of Kerman, Razi University of Kermansheh, and Ferdowsi University of Mashhad.

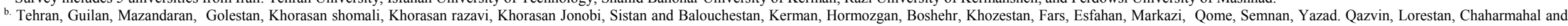
Bakhtiari, Kohgiluyeh Boyer, Kurdistan, Kermansheh, Ilam, Hamedan, Western Azerbaijan, East Azarbaijan, Ardabil, Zanjan university.

c. survey includes 5 universities from whole of Iran: Tehran university, Isfahan University of Technology, Shahid Bahonar University of Kerman, Razi University of Kermansheh, Ferdowsi University of Mashhad

d. Please refer to the appendix 1 for details of studies included to the systematic review and meta-analysis 


\begin{tabular}{|c|c|c|c|c|c|c|c|c|c|c|c|c|}
\hline \multirow[t]{2}{*}{ Study ID } & \multirow[b]{2}{*}{ First author } & \multirow{2}{*}{$\begin{array}{l}\text { Year of } \\
\text { study }\end{array}$} & \multirow[t]{2}{*}{ Study location } & \multirow{2}{*}{$\begin{array}{l}\text { Age in years } \\
\text { (Mean) }\end{array}$} & \multirow[b]{2}{*}{ Sampling methods } & \multirow[b]{2}{*}{$\begin{array}{l}\text { Sample } \\
\text { size }(n)\end{array}$} & \multirow[b]{2}{*}{$\begin{array}{c}\begin{array}{c}\text { Response } \\
\text { rate }(\%)\end{array} \\
\end{array}$} & \multirow[b]{2}{*}{ Daily } & \multirow[b]{2}{*}{$\begin{array}{l}\text { Last } \\
\text { week }\end{array}$} & \multicolumn{3}{|c|}{ Prevalence (\%) } \\
\hline & & & & & & & & & & $\begin{array}{c}\text { Last } \\
\text { month }\end{array}$ & $\begin{array}{l}\text { Last } \\
\text { year }\end{array}$ & Lifetime \\
\hline W31 & Rezahosseini O \& et al & 2008 & Rafsanjan & 21.35 & Random sampling & 1260 & 100 & _ & - & - & - & 12.6 \\
\hline W32 & Rezakhani Moghadam H \& et al & 2012 & Tehran & 22.92 & Stratified random sampling & 977 & 100 & - & - & - & - & 22.76 \\
\hline W33 & Roohafza $\mathrm{H}$ \& et al & 2007 & Isfahan \& Kashan & & Random sampling & 812 & 100 & - & - & - & & 9.48 \\
\hline W34 & Safiri S \& et al & 2015 & Tabriz & & Stratified random sampling & 1730 & 97.3 & - & - & - & $1 \overline{2} .4$ & \\
\hline W35 & Sahraian A \& et al & 2008 & Shiraz & & Random sampling & 971 & 100 & & & 5.9 & & 6.7 \\
\hline W36 & Sargolzayi M \& et al & 2001 & Mashhad & 25.28 & Census & 1126 & 83.45 & 5.08 & _ & _ & _ & 3.9 \\
\hline W37 & Shafiie N \& et al & 2011 & Bam & 21.56 & Random sampling & 760 & 100 & - & - & - & - & 5.7 \\
\hline W38 & Shojaa M \& et al & 2010 & Golestan & 22.1 & Census & 699 & 80 & - & - & - & - & 83.5 \\
\hline W39 & Sohrabi F \& et al & 2006 & Survey ${ }^{\mathrm{a}}$ & 21.03 & Random Cluster Sampling & 8375 & 99.98 & & & 10.3 & 14 & 20 \\
\hline W40 & Taheri E \& et al & 2008 & Mashhad & & Census & 1100 & 85 & 9.8 & - & 3 & & 9.8 \\
\hline W41 & Talaei A \& et al & 2008 & Torbat jaam & $18-24$ & Census & 843 & 100 & 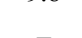 & & & & 19.2 \\
\hline W42 & Taremian F \& et al & 2006 & Tehran & 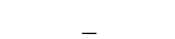 & Random sampling & 2997 & 100 & - & - & $1 \overline{1} .6$ & $1 \overline{5} .7$ & 24.2 \\
\hline W43 & Taremian F \& et al & 2011 & Tehran & - & Random Cluster Sampling & 4000 & 89.55 & - & - & - & - & 18 \\
\hline W44 & Tarrahi MJ \& et al & 2015 & Lorestan & $1 \overline{9} .6$ & Random sampling & 1131 & 95.8 & $\overline{0.8}$ & - & - & - & 18 \\
\hline W45 & Valipour M \& et al & 2009 & Lorestan & Range: $19-27$ & Census & 100 & 100 & - & - & - & - & 21 \\
\hline W46 & Yaghoubi H \& et al & 2011 & Survey ${ }^{\mathrm{b}}$ & & Stratified random sampling & 7330 & 95.12 & - & - & $\overline{9.2}$ & $1 \overline{2} .4$ & 20.4 \\
\hline W47 & Yekkehfallah L \& et al & 2009 & Qazvin & $2 \overline{0.4}$ & Random Cluster Sampling & 200 & 100 & - & - & - & & 1.5 \\
\hline W48 & Zahedi R \& et al & 2016 & Kerman & 20.5 & $\begin{array}{l}\text { multistage non-random } \\
\text { sampling }\end{array}$ & 1730 & 83.6 & - & - & $\begin{array}{l}- \\
-\end{array}$ & $1 \overline{3} .2$ & - \\
\hline W49 & Zarrabi $\mathrm{H} \&$ et al & 2006 & Gilan & 22.12 & Random sampling & 845 & 97.87 & & & 9.6 & & 25.8 \\
\hline
\end{tabular}

a. Survey includes 5 universities from Iran: Tehran University, Isfahan University of Technology, Shahid Bahonar University of Kerman, Razi University of Kermansheh, and Ferdowsi University of Mashhad.

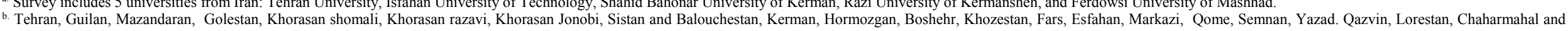
Bakhtiari, Kohgiluyeh Boyer, Kurdistan, Kermansheh, Ilam, Hamedan, Western Azerbaijan, East Azarbaijan, Ardabil, Zanjan university.

c. survey includes 5 universities from whole of Iran: Thran university, Isfahan University of Technology, Shahid Bahonar University of Kerman, Razi University of Kermansheh, Ferdowsi University of Mashhad 
A total sample size of 81610 college students in mixedgender was included from 60 studies. Also, 34 studies reported prevalence in male $(n=33514)$ and 26 in female $(\mathrm{n}=46307)$, respectively.

The highest prevalence of lifetime smoking (at least once in a lifetime) in mixed-gender studies was reported in Shojaa et al. study in Golestan province that was equal to $83.5 \%$ (11) and the lowest prevalence was $1.5 \%$ in Qazvin (12). The highest prevalence of lifetime smoking in males was $70.2 \%$ in the Ahmadi et al. study from Shiraz (13); In females, it was $31.7 \%$ in the Yaghoubi et al. study (14). The lowest prevalence of lifetime smoking in males and females were $2.38 \%$ and $0.86 \%$ in Qazvin (12) (Yekkehfallah et al.), respectively. The average age of males (reported in 32 studies) and females (reported in 26 studies) were 22.35 and 21.2 years, respectively. The mean age of mixed samples was 21.7 years that reported in 58 studies.

\section{Heterogeneity}

According to the result of the chi-square test and $I^{2}$ index, there was a substantial between-study heterogeneity; they report the prevalence of cigarette smoking in at least once in a lifetime $\left(I^{2}=98.65 \%, \mathrm{p}<0.001\right)$, at least once in the last year $\left(I^{2}=97.2 \%, \mathrm{p}<0.001\right)$, at least once in the last month $\left(I^{2}=98.92 \%, \mathrm{p}<0.001\right)$ and daily use in the last month $\left(I^{2}=98.8 \%, \mathrm{p}<0.001\right)$. Consequently, the random effect model was used in this study.

\section{Subgroup Analysis}

Based on the random effect model, the pooled prevalence of cigarette smoking at least once in a lifetime in college students was 19\% (95\% CI: 17-22) (Table 2). Also, the pooled prevalence of cigarette smoking at least once in a lifetime in males and females was $28 \%$ (95\% CI: 23-34) and 9\% (95\% CI: 6-13), respectively (Table 2). The pooled prevalence of cigarette smoking at least once in the last year in college students was $11 \%$ (95\%CI: 9-3), also in males and females were $18 \%(95 \% \mathrm{CI}$ : 16-21) and $7 \%$ (95\% CI: 5-8) respectively (Table 2).

Also, the pooled prevalence of cigarette smoking at least once use in last month in both gender and male and female subgroups was 10\% (95\% CI: 7-12), 20\% (95\% CI: $15-26)$ and 5\% (95\% CI: 3- 8), respectively (Table 2). The pooled prevalence of cigarette smoking daily use in last month in both gender and male and female subgroups was 6 (95\% CI: 4-10), 12\% (95\% CI: 2-28) and 2\% (95\% CI: 0-6), respectively (Table 2).

Moreover, the pooled estimate prevalence of lifetime cigarette smoking by sampling methods, in random sampling, random cluster sampling, census, and stratified random sampling were $25.63 \% \quad(95 \%$ CI: $19.62-31.64)$, $20.05 \%$ (95\% CI: $11.30-28.80), 17.60 \%$ (95\% CI: $8.75-$ $26.44)$ and $20.10 \%$ (95\% CI: $18.70-21.51)$, respectively.

Table 2. The result of pooled prevalence of smoking in related subgroups in college students of Iran

\begin{tabular}{|c|c|c|c|c|c|c|}
\hline Subgroup & & $\begin{array}{c}\text { No. of } \\
\text { Included studies }\end{array}$ & $\begin{array}{l}\text { Pooled Prevalence } \\
\text { (Random Effect) }\end{array}$ & $95 \% \mathrm{CI}$ & $\mathrm{I}^{2}$ & $\mathrm{P}$ value for $\mathrm{I}^{2}$ \\
\hline \multirow{3}{*}{$\begin{array}{l}\text { At least once in } \\
\text { the Life time }\end{array}$} & & 44 & 0.19 & $0.17-0.22$ & 98.65 & $<0.001$ \\
\hline & Male & 22 & 0.28 & $0.23-0.34$ & 98.58 & $<0.001$ \\
\hline & Female & 20 & 0.09 & $0.06-0.13$ & 98.72 & $<0.001$ \\
\hline \multirow{3}{*}{$\begin{array}{l}\text { At least once in } \\
\text { the Last year }\end{array}$} & & 10 & 0.11 & $0.09-0.13$ & 91.52 & $<0.001$ \\
\hline & Male & 4 & 0.18 & $0.16-0.21$ & 79.30 & $<0.001$ \\
\hline & Female & 4 & 0.07 & $0.05-0.08$ & 73.95 & 0.015 \\
\hline \multirow{3}{*}{$\begin{array}{l}\text { At least once in } \\
\text { the Last month }\end{array}$} & & 20 & 0.10 & $0.07-0.12$ & 98.63 & $<0.001$ \\
\hline & Male & 12 & 0.20 & $0.15-0.26$ & 97.73 & $<0.001$ \\
\hline & Female & 12 & 0.05 & $0.03-0.08$ & 98.00 & $<0.001$ \\
\hline \multirow{3}{*}{$\begin{array}{l}\text { Daily use in the } \\
\text { Last month }\end{array}$} & & 15 & 0.06 & $0.04-0.10$ & 98.87 & $<0.001$ \\
\hline & Male & 5 & 0.12 & $0.02-0.28$ & 98.82 & $<0.001$ \\
\hline & Female & 4 & 0.02 & $0.01-0.06$ & 95.49 & $<0.001$ \\
\hline
\end{tabular}

Table 3. Evaluation of effect of every included study on the pooled prevalence of cigarette smoking using sensitivity analysis

\begin{tabular}{|c|c|c|c|c|c|c|c|}
\hline \multirow[b]{2}{*}{ Subgroup } & \multicolumn{3}{|c|}{ Pre-Sensitivity Analysis } & \multicolumn{4}{|c|}{ Post-Sensitivity Analysis } \\
\hline & $\begin{array}{c}\text { No. of } \\
\text { Included studies }\end{array}$ & $\begin{array}{l}\text { Pooled Prevalence } \\
\text { (Random Effect) }\end{array}$ & $95 \% \mathrm{CI}$ & $\begin{array}{c}\text { Upper and Lower } \\
\text { of } \mathrm{EF}^{\mathrm{a}}\end{array}$ & $\begin{array}{l}\text { Pooled Prevalence } \\
\text { (Random Effect) }\end{array}$ & $95 \% \mathrm{CI}$ & $\begin{array}{c}\text { Excluded } \\
\text { Studies }\end{array}$ \\
\hline \multirow{2}{*}{$\begin{array}{l}\text { At least once in } \\
\text { the Life time }\end{array}$} & 45 & 19 & $17-22$ & Upper & 20.76 & $18.07-23.4$ & $\mathrm{~W} 47^{\mathrm{b}}$ \\
\hline & & & & Lower & 19.3 & $17.2-21.5$ & W38 \\
\hline \multirow{2}{*}{$\begin{array}{l}\text { At least once in } \\
\text { the Last year }\end{array}$} & 12 & 11 & $9-12$ & Upper & 14.5 & $11.8-17.3$ & W28 \\
\hline & & & & Lower & 11.1 & $8.07-14.1$ & W14 \\
\hline \multirow{2}{*}{$\begin{array}{l}\text { At least once in } \\
\text { the Last month }\end{array}$} & 18 & 10 & $7-12$ & Upper & 10.7 & $8.6-12.9$ & W17 \\
\hline & & & & Lower & 9.2 & $7.2-11.1$ & W14 \\
\hline \multirow{2}{*}{$\begin{array}{l}\text { Daily use in the } \\
\text { last month }\end{array}$} & 13 & 6 & $4-10$ & Upper & 8.2 & $5.7-10.7$ & W8 \\
\hline & & & & Lower & 6.2 & $4.1-8.2$ & W55 \\
\hline
\end{tabular}

a. EF: effect size; the upper and lower limit of effect size (pooled prevalence) in post-sensitivity analysis after omitting each study

b. Please refer to the appendix 1 for details of studies included to the systematic review and meta-analysis 
The point estimate of one study with multistage random sampling was $31.50 \%$ (95\% CI: 27.79-35.21).

\section{Sensitivity Analysis}

In the sensitivity analysis, the pooled estimation of smoking lifetime prevalence was calculated after excluding every study. The lower and higher pooled prevalence estimation in the sensitivity analysis was 19 (95\% CI: 16.4-21.6) after omitting the Shojaa $M$ et al. study and 20.76 (95\% CI: 18.07-23.44) after omitting the Yekkehfallah L et al. study, respectively (Table 3 ).

\section{Meta-Regression Analysis}

Meta-regression was used to investigate the effects of suspected variables in heterogeneity in every duration and frequency of cigarette smoking use. According to the multivariate model, there was a significant association between the year of study $(\beta=-13.1, p=0.01)$ and sampling method $(\beta=-12.8, p=0.01)$ and daily use in the last month (Table 4).

\section{Discussion}

We systematically reviewed the prevalence of smoking among university students in Iran. There are four main findings: (1) We found that among the 60 studies that reported the prevalence of smoking in mixed-gender $(81610$ college students), the prevalence of smoking lifetime use (at least once in a lifetime) in total, men and women college students is $19 \%, 28 \%$ and $9 \%$, respectively. (2) Prevalence of smoking at least once in last month in both gender and male and female subgroups were $10 \%, 20 \%$, and $5 \%$, respectively (3). Prevalence of daily smoking in the last month in both genders, male and female subgroups was $6 \%, 12 \%$, and $2 \%$, respectively (4). The prevalence of smoking in the last year in both genders, male and female subgroups was $11 \%, 18 \%$ and $7 \%$, respectively. The prevalence of cigarette smoking in males was considerably more than that of females in all durations.

Much research has been conducted to compare smoking among university students with other populations. A metaanalysis of the prevalence of current cigarette smoking (this is similar to daily use in last month in the present study) in the general population of west of Iran showed that prevalence of smoking in the total sample, men and women is $11.75 \%, 22.9$ and 0.6 , respectively (15). In the previous meta-analysis of smoking use in college students of Iran in 2013, the pooled prevalence was reported $11.6 \%$ in mixed-gender and $19.5 \%$ and $2.2 \%$ in male and female college students; it shows the significant increase in both genders in comparison with the results of this study (16). Moreover, various studies in Iran reported the prevalence of smoking in 15-64 years old population from $9.7 \%$ to $13.9 \%$ in both genders, $19 \%$ to $24 \%$ in males and 0.3 to $0.9 \%$ in females $(3,17)$. Therefore, the prevalence of daily use in the last month in university students is consistent with the general population in Iran, but is higher than youth (15-34 years old) that reported $8.3 \%$ (3). This difference has variant causes; several studies indicated that some factors such as having smoking friends, stress, being far from family and entertainment, living alone, curiosity and seeking pleasure, an extended course of education, despair from coming career and use as a fun and enjoyment $(18,19)$. Smoking was significantly higher among students living away from their families than those living with families (20). In the contrary, some factors such as friends, parental supervision, and personal expenditure by them and extracurricular activities like sports are reported as protective factors (21).

Smoking prevalence in adolescents and students as a key and influential population in comparison with university students is so important. In a systematic review study, the prevalence of lifetime tobacco use including cigarettes, pipe and hookah among high school students in both gender, men and women were $21 \%, 30.9 \%$ and $14 \%$, respectively (22). On the other hand, the pooled estimates for meta-analysis of cigarette smoking (not mention to duration) in Iranian adolescents (14-19 years old) were $16.8 \%$ (21). A meta-analysis of smoking status in Iranian male adolescents found almost one-third of male adolescents $(34.2 \%)$ have experienced smoking; this means lifetime prevalence. These results showed lifetime prevalence in high school students correspond to university students. Therefore, it is concluded that maybe the onset of smoking in university student was in the school (23). Smoking is a behavior that generally begins in adolescence. Most of the smokers begin smoking in secondary school. Moreo-

Table 4. Assessing the effect of study variables on the pooled prevalence of cigarette smoking in college student in Iran using meta-regression analysis

\begin{tabular}{|c|c|c|c|c|c|c|c|}
\hline \multirow[b]{2}{*}{ Prevalence } & \multirow[b]{2}{*}{ Variable } & \multicolumn{3}{|c|}{ Univariable Model } & \multicolumn{3}{|c|}{ Multivariable Model } \\
\hline & & $\beta$ & $\mathrm{SE}$ & $\mathrm{p}^{*}$ & $\beta$ & $\mathrm{SE}$ & $p$ \\
\hline \multirow[t]{3}{*}{ At least once in the Life time } & Sample size $^{\mathrm{a}}$ & -4.3 & 4.2 & 0.329 & -4.5 & 4.4 & 0.323 \\
\hline & Year of study & 0.7 & 4.3 & 0.845 & 1.4 & 4.7 & 0.716 \\
\hline & Sampling method ${ }^{\mathrm{b}}$ & 0.26 & 4.9 & 0.934 & 1.1 & 5.4 & 0.842 \\
\hline \multirow[t]{3}{*}{ At least once in the Last year } & Sample size & 13.2 & 7.5 & 0.173 & 16.06 & 8.5 & 0.124 \\
\hline & Year of study & 1.7 & 5.3 & 0.754 & 1.7 & 8.5 & 0.885 \\
\hline & Sampling method & -2.83 & 5.4 & 0.692 & -4.05 & 8.5 & 0.628 \\
\hline \multirow[t]{3}{*}{ At least once in the Last month } & Sample size & 2.8 & 4.7 & 0.543 & 2.4 & 4.6 & 0.618 \\
\hline & Year of study & -0.6 & 3.6 & 0.815 & -3.3 & 3.9 & 0.456 \\
\hline & Sampling method & -4.9 & 3.4 & 0.163 & -6.3 & 3.9 & 0.186 \\
\hline \multirow[t]{3}{*}{ Daily use in the last month } & Sample size & -3.04 & 4.6 & 0.511 & -2.5 & 3.7 & 0.586 \\
\hline & Year of study & -4.9 & 4.8 & 0.382 & -13.1 & 4.7 & 0.011 \\
\hline & Sampling method & -6.08 & 4.5 & 0.237 & -12.8 & 4.6 & 0.017 \\
\hline
\end{tabular}

\footnotetext{
Studies with sample size $>1,000$ versus $<1,000$ as reference.

b. Random sampling, multistage random sampling, stratified random sampling, random cluster sampling vs. census as reference.

${ }^{*}$ p-value $<0.05$ considered significant
} 
ver, about $60 \%$ of smokers in Iran have smoked before the age of 18 years ( 7 ).

Much research has been conducted to confirm smoking among university students across the country. The survey of international comparison of tobacco smoking from 23 countries indicated that the prevalence of current smoking was $6 \%$ to $44.5 \%$ (24). In the other study, smoking in European university students from 13 countries, the prevalence of current smoking in both gender, male and female was $33.9 \%, 35 \%$ and $33 \%$ (24). In addition, there was a wide range variety of smoking prevalence among college students of Eastern Mediterranean region countries and some Arabic countries. Prevalence of cigarette smoking among male Kuwait university students reported $42.2 \%$ smoked daily a mean of 31 cigarettes per day (25) in Jordan; current smoking was $16.5 \%$ (26) in Syria was 20.75\%. (20) and in KSA and Lebanon (5) were 24\% and $18.9 \%$, respectively. In Saudi Arabia, the prevalence of cigarette smoking among female college students was reported $13.3 \%$ and among college departments, the highest prevalence was in the respiratory care department by $25 \%$ (27) that is much higher than in Iran (28). The prevalence of smoking in university students in Iran is lower than more countries in the world and lower than their counterparts in Arabic and neighboring countries. Maybe that means an alarm, this result show cigarette smoking shift to other products such as water pipe or other substance, because the water pipe is so acceptable and adaptable with Iranian culture and environment. The prospective study conducted in college students in the United States indicated that current hookah use in the past 30 days predicts cigarette smoking progression among college smokers (27).

We also found that the prevalence of cigarette smoking in males was considerably more than that of females. This pattern was according to the results of all studies in Iran and other countries in the university student and other populations. The result of assessing the gender-related responses to smoking cessation indicated that women worried more about smoking-related illnesses than men (26). The results of our study subject to some limitations due to existing high heterogeneity in all study subgroups pooled prevalence. Consequently, the result of this meta-analysis should be used and interpreted with consideration of these limitations. One possible cause for heterogeneity could be due to the variety of questionnaires used in included studies. Most of the included studies in the meta-analysis failed to follow and report the standard questionnaire with acceptable validity and reliability for measuring substance and smoking use. Another cause may be the high variety of smoking prevalence in the provinces of Iran that may be another source of heterogeneity.

\section{Conclusion}

This meta-analysis showed that the pooled prevalence of cigarette smoking among female and male college students of Iran is lower than in other countries but high in comparison with its prevalence in the general population who are aged 15-34 years in Iran. In comparison with other countries may be a shift in use of other products such as water pipe. The most common risk factors are having smoker friends and lack of family support. However, as the society has high expectations of this group, even low smoking prevalence in this group is not acceptable. Therefore, providing a comprehensive program with high efficiency, which covers all aspects of life, is essential. Implementation of prevention programs such as 'life skills training program', "peer education" and "social marketing", in addition to predicting a way of assessment and monitoring of prevalence smoking and other substance in university students are suggested.

\section{Conflict of Interests}

The authors declare that they have no competing interests.

\section{References}

1. Mohammadpoor Asl A, Fakhari A, Rostami F, Pourafkary N. Cigarette smoking among Iranian adolescents. Iran J Psychiatry Behav Sci. 2007;1(1):30-5.

2. WHO. Global Burden of Disease Study 2010: WHO; 2012 [cited 2016 5/30/2016]. Available from: http://ash.org/global-burden-of-diseasestudy-2010/.

3. Ardeshiri MJ, Moosazadeh M, Masouleh MF, Masouleh MF, Kiani A, Fakhri M. Prevalence of smoking in 15-64 years old population of north of Iran: meta-analysis of the results of non-communicable diseases risk factors surveillance system. Acta Med Iran. 2013;51(7):494-500.

4. Rezaei F, Noroozi A, Armoon B, Farhoudian A, Massah O, Sharifi H, et al. Social determinants and hepatitis $\mathrm{C}$ among people who inject drugs in Kermanshah, Iran: Socioeconomic status, homelessness, and sufficient syringe coverage. J Subst Use. 2017;22(5):474-8.

5. Tamim H, Terro A, Kassem H, Ghazi A, Khamis TA, Hay MMA, et al. Tobacco use by university students, Lebanon, 2001. Addiction. 2003;98(7):933-9.

6. Haddad LG, Malak MZ. Smoking habits and attitudes towards smoking among university students in Jordan. Int $J$ Nurs Stud. 2002;39(8):793-802.

7. Al-Nefisah OS, Al-Ghaneem SG. The prevalence of smoking among male students of Majmaah University, J Taibah Univ Med Sci. 2016;11(2):175-178.

8. Taheri E, Ghorbani A, Salehi M, Sadeghnia HR. Cigarette smoking behavior and the related factors among the students of mashhad university of medical sciences in iran. Iran Red Crescent Med J 2015;17(1):1-6.

9. Ahmadi J, Khalili H, Jooybar R, Namazi N, Aghaei P. Cigarette smoking among Iranian medical students, resident physicians and attending physicians. Eur J Med Res. 2001;6(9):406-8.

10. Alizade H, Sharifi H, Naderi Z, Ghanbarpour R, Bamorovat M, Aflatoonian MR. High Frequency of Diarrheagenic Escherichia coli in HIV-Infected Patients and Patients with Thalassemia in Kerman, Iran. J Int Assoc Provid AIDS Care. 2017;16(4):353-8.

11. Shojaa M, Qorbani M, Jouybari LM, Sanagoo A, Mohebi R, Bamyar $\mathrm{R}$, et al. Prevalence of smoking among the students resided at dormitories in Golestan university of medical sciences, Iran. Bangladesh J Medical Sci. 2014;13(4):460-5.

12. Yekkehfallah L, Momeni A, Torkashvand A, Jahani Hashemi H. Factors Associated with Ecstasy Use in Students of Qazvin University of Medical Sciences. Hayat. 2009;15(2):73-80.

13. Ahmadi J, Yazdanfar F. Current substance abuse among Iranian university students. Addict Disord Their Treat. 2002;1(2):61-4.

14. Yaghubi H, Taremian F, Peyravi H, Zafar M. Drug use Prevalence among College Students of Ministry of Sceince, Research and Technology, Iran (2012). Research on Addiction. 2015;8(32):9-36.

15. Moosazadeh M. Meta-analysis of prevalence of smoking in 15-64year-old population of west of Iran. Int J Prev Med. 2013;1(1):110814.

16. Haghdoost AA, Moosazadeh M. The prevalence of cigarette smoking among students of Iran's universities: A systematic review and meta-analysis. J Res Med Sci. 2013;18(8):717-25. 
17. Moosazadeh M, Salami F, Movahednia M, Amiri MM, Afshari M. Prevalence of smoking in northwest Iran: a meta-analysis. Electron Physician. 2014;6(1):734-40.

18. Majidpur A, Hamidzadeh Y, Abasgholizade N, Salehy E. Prevalence and Causes of Tendency to Cigarette Smoking among Students in Ardabil University of Medical Sciences. J Ardabil Univ Med Sci. 2005;5(3):266-70.

19. Nazemi S, Chaman R, Davardust N. Prevalence and Reasons of Inclination towards Smoking among University Students. Knowl Health. 2012;7(3):107-11.

20. Al-Kubaisy W, Abdullah NN, Al-Nuaimy H, Kahn SM, Halawany G, Kurdy S. Factors Associated with Smoking Behaviour among University Students in Syria. Procedia Soc Behav Sci. 2012;38:59-65.

21. Ansari-Moghaddam A, Rakhshani F, Shahraki-Sanavi F, Mohammadi M, Miri-Bonjar M, Bakhshani N-M. Prevalence and patterns of tobacco, alcohol, and drug use among Iranian adolescents: A meta-analysis of 58 studies. Child Youth Serv Rev. 2016;60:68-79.

22. Rahimi Movaghar A, Hefazi M, Amin Esmaeili M, Sahimi Izadian E, Yusefi Nuraei R. smoking life time prevalence in high school student: A systematic review. Payesh. 2012;11(3):337-49.

23. Nazarzadeh M, Bidel Z, Ayubi E, Bahrami A, Jafari F, Mohammadpoorasl A, et al. Smoking status in Iranian male adolescents: A cross-sectional study and a meta-analysis. Addict Behav. 2013;38(6):2214-8.

24. Steptoe A, Wardle J, Cui W, Bellisle F, Zotti A-M, Baranyai R, et al. Trends in smoking, diet, physical exercise, and attitudes toward health in European university students from 13 countries, 1990-2000. Prev Med. 2002;35(2):97-104

25. Alansari B. Prevalence of cigarette smoking among male Kuwait University undergraduate students. Psychol Rep. 2005;96(3 suppl):1009-10.

26. Kofahi MM, Haddad LG. Perceptions of lung cancer and smoking among college students in Jordan. J Transcult Nurs. 2005;16(3):24554.

27. Doran N, Godfrey KM, Myers MG. Hookah use predicts cigarette smoking progression among college smokers. Nicotine Tob Res. 2015;17(11):1347-53.

28. Ansari K, Farooqi FA. Comparison and prevalence of smoking among Saudi females from different Departments of the College of Applied Medical Sciences in Dammam. Int $J$ Health Sci. 2017;11(5):56-62. 